\title{
Arginine Catabolic Mobile Elements in Livestock-Associated Methicillin-Resistant Staphylococcal Isolates From Bovine Mastitic Milk in China
}

\author{
Chao Tong ${ }^{1}$, Zhaowei $\mathrm{Wu}^{1}$, Xin Zhao ${ }^{1,2 *}$ and Huping Xue ${ }^{1 *}$ \\ ${ }^{1}$ College of Animal Science and Technology, Northwest A\&F University, Yangling, China, ${ }^{2}$ Department of Animal Science, \\ McGill University, Montreal, QC, Canada
}

OPEN ACCESS

Edited by:

Patrick Rik Butaye,

Ross University School of Veterinary Medicine, Saint Kitts and Nevis

Reviewed by:

Maria Angeles Argudín, Free University of Brussels, Belgium

Jean-Yves Madec,

Agence Nationale de Sécurite

Sanitaire de l'Alimentation,

de l'Environnement et du Travail

(ANSES), France

*Correspondence:

Xin Zhao

xin.zhao@mcgill.ca

Huping Xue

xuehuping@hotmail.com

Specialty section:

This article was submitted to

Antimicrobials, Resistance

and Chemotherapy,

a section of the journal

Frontiers in Microbiology

Received: 20 January 2018 Accepted: 01 May 2018

Published: 16 May 2018

Citation:

Tong $C$, Wu Z, Zhao $X$ and Xue $H$ (2018) Arginine Catabolic Mobile Elements in Livestock-Associated Methicillin-Resistant Staphylococcal Isolates From Bovine Mastitic Milk in China. Front. Microbiol. 9:1031. doi: 10.3389/fmicb.2018.01031
The arginine catabolic mobile element (ACME) facilitates colonization of staphylococci on skin and mucous membranes by improving their tolerances to polyamines and acidic conditions. ACME is inserted in tandem with the SCCmec element and Staphylococcus epidermidis has been proposed to be a reservoir of ACME for other staphylococci. In this study, we investigated the existence of ACME in 146 staphylococcal isolates from mastitic milk and found 21 of them carried ACME. Almost half of the investigated S. epidermidis isolates contained the element. The whole genome of a S. epidermidis strain Y24 with ACME was further sequenced and the ACME-SCCmec composite island was assembled. This composite island is $81.3 \mathrm{~kb}$ long and consisted of 77 ORFs including a methicillin resistance gene mecA, a type II' ACME gene cluster, a virulence gene p/s and eight heavy metal tolerance genes. Wide existence of ACME in livestockassociated staphylococci from this study and a potential risk of spreading ACME among different staphylococcal species warrant close monitoring and further studies.

Keywords: livestock-associated staphylococci, arginine catabolic mobile element, SCCmec, heavy metal tolerance, methicillin resistance

\section{INTRODUCTION}

The opportunistic pathogen Staphylococcus epidermidis is a permanent and common commensal bacterium of skin and mucosa. As the most important cause of infections on indwelling medical devices (Otto, 2009), S. epidermidis has become the third most common source of nosocomial infections (Sievert et al., 2013; Rupp, 2014). Besides its pathogenicity, S. epidermidis is proposed to be a main reservoir of antimicrobial resistance genes and virulence genes for Staphylococcus aureus (Otto, 2013), by horizontal transferring of mobile genetic elements such as Staphylococcal chromosomal cassette mec (SCCmec) and arginine catabolic mobile element (ACME) (Diep et al., 2006; Thurlow et al., 2013; Xue et al., 2017).

Arginine catabolic mobile element is inserted in tandem with the SCCmec (ACME-SCCmec composite island) and contains an arc cluster, an $o p p-3$ cluster and spe G gene. ACME allotypes are defined by the presence or absence of the $\operatorname{arc}$ and $o p p-3$ gene clusters (type I, $\operatorname{arc}^{+} o p p-3^{+}$; type II, $a r c^{+} o p p-3^{-}$; type III, $\operatorname{arc}^{-} o p p-3^{+}$). Carriage of ACME also improves the capacity and fitness of S. aureus to colonize the skin and mucosa (Diep et al., 2008). The arc cluster mediates the arginine-deiminase pathway that converts L-arginine to L-ornithine for production of both ATP and ammonia, the latter is responsible for enhanced acid tolerance of staphylococci on human 
skin (Alonzo and Torres, 2013; Thurlow et al., 2013). The spe $\mathrm{G}$ encodes a spermine/spermidine $\mathrm{N}$-acetyltransferase (SpeG), which detoxifies polyamines that are produced by all living organisms. SpeG allows the strains to evade the toxicity of polyamines secreted on the human skin and to potentiate its colonization and infection.

Arginine catabolic mobile element was first identified in S. aureus USA300 in 2006 (Diep et al., 2006) and was proposed to contribute to successful spread of this community clone in North America and Europe (Talan et al., 2011; Thurlow et al., 2012; Glaser et al., 2016). ACME has been reported in the staphylococcal isolates from humans in several Asian countries. The earliest report of the ACME element in Asia was in Japan, 2007 (Shibuya et al., 2008), and an increasing trend was observed afterward (Onishi et al., 2013; Urushibara et al., 2016; Aung et al., 2017). In addition to Japan, $38.7 \%$ of 360 S. aureus sequence type 239-like isolates in Australia (obtained between 1997 and 2008) was reported to carry an ACME (Espedido et al., 2012), and 12.7\% ST239 strains isolated between 2000 and 2010 in Singapore also carried the ACME element (Hon et al., 2013). A later evolutionary study found that the local clone ST239 in Singapore began to increase from 2007 onward after they acquired ACME (Hsu et al., 2015). The first case of ACME element in Korea was reported in 2016 (Jung et al., 2016). The presence of ACME in the staphylococcal isolates from animals was much less reported. A previous study reported that almost half of $S$. epidermidis isolates (12/22) in pigs contained the arc cluster (Argudín et al., 2015). In addition, McManus et al. (2015) detected the ACME in staphylococcal isolates from companion animals. However, the report about ACME in staphylococcal isolates from both humans and animals in China is scarce.

In this study, we found that the ACME element widely existed in livestock isolated staphylococcal isolates, especially in S. epidermidis. The whole genome of an S. epidermidis isolate Y24 was then sequenced. An ACME-SCCmec composite island with a length of $81.3 \mathrm{~kb}$ was found in the genome of Y24, conferring this bacterium with $\beta$-lactam antibiotics resistance and heavy metal resistance. Based on comparative analyses, we found the ACMESCCmec composite island in Y24 was phylogenetically close to the element of $S$. aureus strains in Germany and Denmark.

\section{MATERIALS AND METHODS}

\section{Bacterial Isolates and ACME Screening}

In the year of 2015, a total of 146 staphylococcal isolates were collected from Holstein cow milk with clinical mastitis at three local dairy farms in Shaanxi province, Northwest China. They were screened for the presence of ACME-arcA and ACME$o p p 3 A B$ genes by PCR (Diep et al., 2008). Primer sequences are listed in the Supplementary Table S1. All PCR products were sequenced by Sanger sequencing.

\section{Whole Genome Sequencing}

Staphylococcus epidermidis strain Y24 was identified by $16 \mathrm{~S}$ rRNA sequencing and whole genome sequencing (WGS). The genomic DNA library with an average insertion size of $500 \mathrm{bp}$ was prepared and paired-end sequencing was performed on the Illumina Hiseq 2000 platform. In order to obtain high quality reads for assembly, low quality reads and adaptor sequences were filtered by readfq.v5 (The Beijing Genomics Institute, China). WGS sequencing reads were assembled by the SOAPdenovo software (version 2.04) using the available genome sequence of S. epidermidis ATCC 12228 as reference guided assembling (Li et al., 2010).

\section{Assembly and Identification of SCC Elements in Y24}

To find SCC elements in Y24 strain, each scaffold of Y24 was searched for orfX region, $m e c A$ gene and $c c r$ gene complex using the BLASTN (version 2.6.0+) software. All positive scaffolds were aligned against the SCCmec IVa of S. aureus strain R99 (GenBank accession no. KF234240.1) to verify their genetic organization. All the gaps were closed using PCR amplification. Gene prediction and functional annotation were accomplished using the Rapid Annotations Subsystems Technology (RAST) server (version 2.0) (Aziz et al., 2008). Then, the nucleotide sequences of the predicted genes were analyzed by BLAST against the NCBI nucleotide collection (nr/nt) database and the nonredundant protein sequence database. Primer sequences are listed in the Supplementary Table S1.

\section{PCRs for Detecting Excision of SCC Elements and ACME}

PCR reactions were performed for investigating excision of SCC elements, ACME and their composite islands by detecting the extrachromosomal circular intermediates, according to the method described by Ito et al. (Ito et al., 1999). A positive PCR strand could be observed if an excision occurs, by using the primer pairs of $1 F+1 R, 2 F+2 R, 3 F+3 R$, and $4 F+4 R$ for detecting single SCC elements, or the primer sets $2 \mathrm{~F}+1 \mathrm{R}, 3 \mathrm{~F}+1 \mathrm{R}$, $4 \mathrm{~F}+1 \mathrm{R}, 3 \mathrm{~F}+2 \mathrm{R}, 4 \mathrm{~F}+2 \mathrm{R}$, and $4 \mathrm{~F}+3 \mathrm{R}$ for detecting composite $\mathrm{SCC}$ elements. The primer sequences are listed in Supplementary Table S1. Y24 strain was grown in the brain heart infusion (BHI) broth. Extracted genomic DNA of Y24 from logarithmic phase cultures was used as template. The products were then cloned into a pEASY-Blunt Zero vector (Transgen, China) for Sanger sequencing.

\section{Minimum Inhibitory Concentrations (MIC) Determinations}

Minimum inhibitory concentrations for the antimicrobial agents were performed by the standard agar dilution method according to Clinical and Laboratory Standards Institute (CLSI) guidelines in the year of 2015 (Clinical Laboratory Standards Institute [CLSI], 2015). Because oxacillin-susceptible mecA-positive Staphylococci can be converted to oxacillinresistant phenotype under oxacillin induction (Liu et al., 2016), strain Y24 was subjected to oxacillin induction by serial passages under oxacillin gradients as $0,0.5,1,2$, and $4 \mathrm{mg} / \mathrm{L}$ from day 0 to day 4 . MICs of heavy metal ions were determined as previously described (Xue et al., 2015). MHA (MuellerHinton agar) plates with different final concentrations of heavy 
metal ions were provided $\mathrm{NaAsO}_{2}$ for arsenic, $\mathrm{ZnSO}_{4} \cdot 7 \mathrm{H}_{2} \mathrm{O}$ for zinc, $\mathrm{CuSO}_{4} \cdot 5 \mathrm{H}_{2} \mathrm{O}$ for copper, $\mathrm{Cd}\left(\mathrm{NO}_{3}\right)_{2} \cdot 4 \mathrm{H}_{2} \mathrm{O}$ for cadmium, $\mathrm{Pb}\left(\mathrm{CH}_{3} \mathrm{COO}\right)_{2} \cdot 3 \mathrm{H}_{2} \mathrm{O}$ for lead and $\mathrm{HgCl}_{2}$ for mercury.

\section{Bioinformatics Analyses}

In order to determine phylogenetic relations among the ACMESCCmec composite island in Y24 and other reported composite SCCs, the NCBI nucleotide blast software was used for genome alignments in the $\mathrm{nr} / \mathrm{nt}$ and wgs databases with default parameters (accessed on May 12th, 2017). The query sequence was the identified $81.3 \mathrm{~kb}$ nucleotide sequence of ACME-SCCmec composite island in Y24. The comparison of different composite SCCs was conducted using BLASTN with the softwares Mauve (Darling et al., 2010) and Easyfig (Sullivan et al., 2011).

\section{RESULTS}

\section{Distribution of ACME Element in Livestock-Associated Staphylococci}

In order to find potential distributions of ACME element in livestock-associated staphylococci, a total of 146 staphylococcal isolates from three dairy farms in Northwestern China were screened (Table 1). Approximately 14\% (21/146) of them possessed ACME ( 9 for type I, 2 for type II or II' and 10 for type III). Most of the ACME positive isolates (15/21) distributed in a same farm. All of the 9 type I ACME elements were located in S. epidermidis, while 10 type III ACME elements were distributed in four different staphylococcal species (Table 1). Eleven out of 24 S. epidermidis isolates contained ACME element, while no ACME was found in any $S$. agnetis or S. warneri isolates.

\section{The ACME-SCCmec Composite Island and Resistant Features of S. epidermidis Y24}

Because almost half of the investigated S. epidermidis isolates contained the ACME element, one of them, Y24, which was resistant to a range of antimicrobial drugs and heavy metals (Tables 2, 3), was chosen for WGS. The WGS data of $399 \mathrm{Mb}$ from Y24, giving approximately 140-fold genome coverage, were generated and assembled into 140 contigs and joined into 56 scaffolds. Among them, five scaffolds were identified as sections of the ACME-SCCmec composite island and six PCRs were performed to close the gaps between/in these scaffolds (Figure 1 and Supplementary Table S1). Finally, the full length of ACMESCCmec composite island of Y24 was determined to be $81.3 \mathrm{~kb}$ (GenBank accession no. KY849363). It consisted of an intact SCCmec element, an ACME element and two pseudo-SCC elements designated $\psi$ SCCpls and $\psi$ SCCars (Figure 1). The SCCmec element (orf2 to orf30) comprised a mec gene complex and a $c c r A 2 B 2$ gene complex and was classified as a type IVa SCCmec (International Working Group on the Classification of Staphylococcal Cassette Chromosome Elements, 2009; Wu et al., 2015). The ACME element (orf38 to orf51) was classified as a type ACME II', because it contained an arc gene cluster but lacked an opp-3 cluster and several genetic components surrounding the arc gene cluster. Among 77 predicted open reading frames (ORFs) in the ACME-SCCmec composite island, 10 ORFs were resistance-associated genes (2 for antibiotics and 8 for heavy metals resistance), 6 ORFs were related to DNA transfer (4 insertion sequences and 2 recombinases) and 6 ORFs were related to the arginine-deiminase pathway (Supplementary Table S2). The composite island in Y24 included five integration site sequences including one in $\operatorname{orf} X$.

Y24 displayed multidrug resistance to kanamycin $(\mathrm{MIC}>256 \mathrm{ug} / \mathrm{ml})$, trimethoprim $(\mathrm{MIC}>256 \mathrm{ug} / \mathrm{ml})$, hygromycin B (MIC> $256 \mathrm{ug} / \mathrm{ml})$, cephalothin $(\mathrm{MIC}=64 \mathrm{ug} / \mathrm{ml})$, streptomycin $(\mathrm{MIC}=32 \mathrm{ug} / \mathrm{ml})$ and penicillin $\mathrm{G}$ $(\mathrm{MIC}=16 \mathrm{ug} / \mathrm{ml})$. Though the MIC of Y24 to oxacillin

TABLE 3 | Results of susceptibility testing against heavy metal compounds of Y24.

\begin{tabular}{lccccccc}
\hline Strains (species) & \multicolumn{7}{c}{ MIC (mM) of heavy metal } \\
\cline { 2 - 7 } & As & Cd & Pb & Cu & Zn & Hg \\
\hline Y24 (S. epidermidis) & $>8$ & 0.125 & $>8$ & 2 & 2 & 0.025 \\
RN4220 (S. aureus) & 0.015 & 0.015 & $>8$ & 2 & 2 & 0.05 \\
\hline
\end{tabular}

TABLE 1 | Prevalence of ACME in strains isolated from Holstein cow milk samples.

\begin{tabular}{|c|c|c|c|c|c|c|c|}
\hline Allotype & $\begin{array}{l}\text { S. epidermidis } \\
(n=24)\end{array}$ & $\begin{array}{l}\text { S. haemolyticus } \\
\qquad(n=34)\end{array}$ & $\begin{array}{c}\text { S. aureus } \\
(n=37)\end{array}$ & $\begin{array}{l}\text { S. chromogenes } \\
\qquad(n=19)\end{array}$ & $\begin{array}{c}\text { S. warneri } \\
(n=30)\end{array}$ & $\begin{array}{c}\text { S. agnetis } \\
(n=2)\end{array}$ & Total $(n=146)$ \\
\hline I & 9 & 0 & 0 & 0 & 0 & 0 & 9 \\
\hline || or II' & 1 & 1 & 0 & 0 & 0 & 0 & 2 \\
\hline III & 1 & 3 & 1 & 5 & 0 & 0 & 10 \\
\hline
\end{tabular}

TABLE 2 | Results of susceptibility testing against antibiotics of Y24.

\begin{tabular}{|c|c|c|c|c|c|c|c|c|c|c|c|c|c|}
\hline Strain (species) & NEO & CLI & OXA & VAN & KAN & CEF & TEC & HYG & CIP & STR & GEN & PEN & TMP \\
\hline Y24 (S. epidermidis) & 2 & 4 & 0.5 & 2 & $>256$ & 64 & 2 & $>256$ & 4 & 32 & 0.5 & 16 & $>256$ \\
\hline RN4220 (S. aureus) & 8 & 4 & 0.5 & 1 & $>256$ & 16 & 1 & $>256$ & 4 & 32 & 1 & 0.5 & 0.5 \\
\hline
\end{tabular}

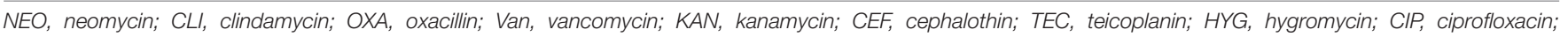
STR, streptomycin; GEN, gentamicin; PEN, penicillin G, TMP, trimethoprim. 

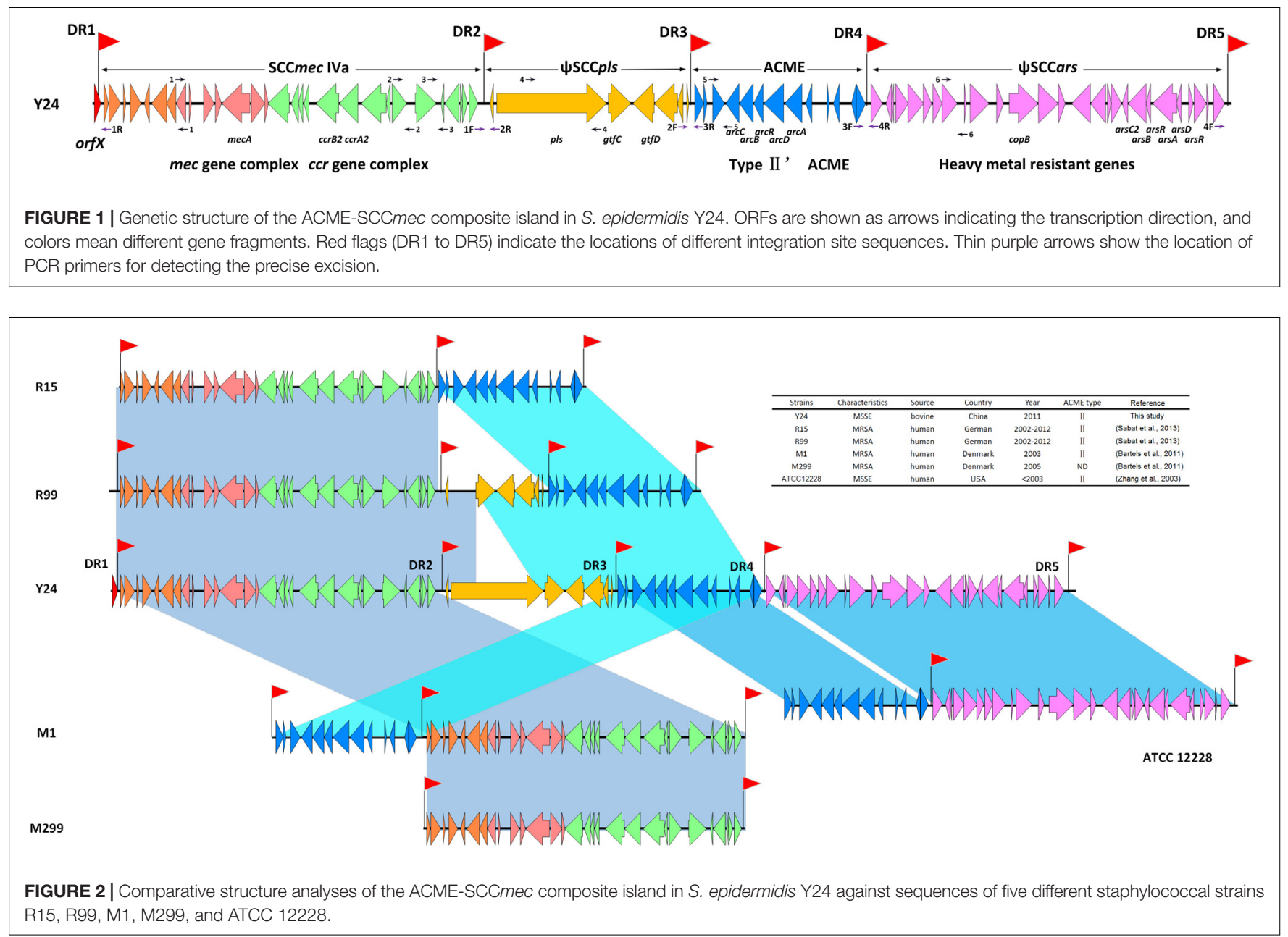

was only $0.5 \mathrm{ug} / \mathrm{ml}$, it displayed an oxacillin resistant phenotype $(\mathrm{MIC}=64 \mathrm{ug} / \mathrm{ml})$ after 4 days of low oxacillin inducing. The genome contains blaZ gene for resistance to penicillin and $m s r A$ and $m p h C$ genes for resistance to macrolide compounds. Genes $d f r A$ and $d r f G$ in the genome contributed to trimethoprim resistance (Supplementary Table S2). The Y24 also displayed a high tolerance to arsenic (MIC> $8 \mathrm{mM}$ ) and lead (MIC> $8 \mathrm{mM})$. The orf62 coding lead resistance and the orf69 to orf 74 coding arsenic resistance could be responsible for the arsenic and lead tolerances of Y24 (Supplementary Table S2). The MICs for mercury, cadmium, zinc and copper ions were 0.025, 0.125, 2, and $2 \mathrm{mM}$, respectively, which may result from expression of orf62 and orf63 (Table 2).

\section{Comparative Analyses of the ACME-SCCmec Composite Island in Y24 With Those in Other Staphylococcal Strains}

Thirty sequences from different staphylococcal strains with the highest similarities with the ACME-SCCmec composite island in Y24 were chosen for detailed analyses (Supplementary Table S3). Among them, the top five sequences showing the highest similarity scores (sequence identity $>99 \%$ ) with the ACME-SCCmec composite island in Y24 were those from strains M1, M299, R99, R15, and ATCC 12228. The accession numbers of them are HM030720, HM030721, KF234240, KF184643, and AE015929, respectively (Figure 2). Strain Y24 shared the SCCmec element (orf2 to orf30) with R15, R99, M1, and M299. It also shared the ACME (orf38 to orf50) with R15, R99, $\mathrm{M} 1$, and ATCC 12228. However, the heavy metal resistance region (orf51 to orf77) was present only in Y24 and ATCC 12228, and absent in R15, R19, M1, or M299. All 30 strains investigated in this study contained a same defensive system as Type I restriction-modification system, which included three USA300 strains as USA300-ISMMS1, USA300_2014.C01, and UA-S391_USA300 (Supplementary Table S3).

Comparative analyses suggested that the SCCmec element or ACME in Y24 could be mobile. In order to check the possibility, PCRs were performed to detect extrachromosomal circular intermediates of SCC elements or ACME between direct repeats (DRs). Strong positive PCR amplicons were detected not only for the primer sets of $1 F+1 R, 2 F+2 R, 3 F+3 R$, and $4 F+4 R$, but also for the primer sets $2 \mathrm{~F}+1 \mathrm{R}, 3 \mathrm{~F}+1 \mathrm{R}, 4 \mathrm{~F}+1 \mathrm{R}, 3 \mathrm{~F}+2 \mathrm{R}, 4 \mathrm{~F}+2 \mathrm{R}$, and $4 \mathrm{~F}+3 \mathrm{R}$, respectively (Supplementary Figure $\mathrm{S} 1$ ). These results confirmed the formation of circular forms in Y24 for single 
SCC elements (SCCmec, $\psi$ SCCpls, ACME, or $\psi$ SCCars) and the composite islands (SCCmec- $\psi \mathrm{SCC} p l s$, SCCmec- $\psi \mathrm{SCC} p l s-$ ACME, etc.).

\section{DISCUSSION}

Sabat et al. (2015) reported ACME elements in two MRSA ST398 isolates from humans. Another study reported the arc cluster, one of the ACME components, existed in the S. epidermidis isolated from pigs (Argudín et al., 2015). Here, we report the presence of the ACME element in different staphylococcal species isolated from livestock, based on both the arc cluster and the opp 3 gene cluster. A previous study found that multiple virulence factors could be transferred between a bovine-originated staphylococci and a hospital-associated staphylococcal strain MRSA252 (Brody et al., 2008). Our recent studies also suggested possible occurrence of a horizontal gene transfer between staphylococci in bovine and staphylococci in humans (Xue et al., 2015, 2017). Based on the detection of extrachromosomal circular intermediates, we found the formation of circular forms in Y24 for both single and composite SCC elements. The large serine recombinases CcrA2B2 encoded in the SCCmec element of Y24 could be responsible for the formation of extrachromosomal circular intermediates. The circular form of ACME element in Y24 suggests the possibility of horizontal transfer of ACME from Y24 to other staphylococci. Thus, the high prevalence of ACME in livestock-associated staphylococcal isolates, especially in S. epidermidis, should be a major concern, since it could be transferred to human-associated staphylococci. In addition, an amplicon corresponding to the primers $1 \mathrm{R}+4 \mathrm{~F}$ proved the ACME, SCCmec and several heavy metal resistant genes coexisted in an extrachromosomal circular, suggesting that they could be transferred as a whole to a new host. The CopB (encoded by $\operatorname{cop} B$, $\operatorname{orf62)}$ was related to copper and lead resistance. In addition, ars $B$ gene (orf70) encodes an arsenic efflux pump protein and ars A (orf72) encodes arsenical pump-driving ATPase that could enhance the arsenic efflux capacity of the ArsB pump (Mukhopadhyay et al., 2002), giving Y24 strong resistance to arsenic (MIC> $>8 \mathrm{mM}$ ). The coexistence of antibiotic resistance genes as well as heavy metal resistance genes in the ACMESCCmec composite island in Y24 could increase its survival both in contaminated environment and under antibiotic pressure (Xue et al., 2015).

The ACME-SCCmec composite island in Y24 contained many other genes such as a plasmin sensitive surface gene ( $p l s$, orf32), a histidine kinase two-component system (orf57 and orf58) and several heavy metal tolerance genes (orf62, orf69 to orf74). Pls

\section{REFERENCES}

Alonzo, F. III, and Torres, V. J. (2013). A lesson in survival: S. aureus versus the skin. Cell Host Microbe 13, 3-5. doi: 10.1016/j.chom.2013.01.001

Argudín, M. A., Vanderhaeghen, W., and Butaye, P. (2015). Antimicrobial resistance and population structure of Staphylococcus epidermidis recovered from pig farms in Belgium. Vet. J. 203, 302-308. doi: 10.1016/j.tvjl.2015.01.008

Aung, M. S., Kawaguchiya, M., Urushibara, N., Sumi, A., Ito, M., Kudo, K., et al. (2017). Molecular characterization of methicillin-resistant protein was a virulence factor in a mouse septic arthritis model (Josefsson et al., 2005). Recently, Bleiziffer et al. (2017) reported that Pls decreased the phagocytosis of $S$. aureus. The same study found that Pls was a glycoprotein and could promote biofilm formation of S. aureus (Bleiziffer et al., 2017). The glycosylation of Pls involved two glycosyltransferases GtfC and GtfD, which were also present in the composite island of Y24 (orf33 and orf34). Co-existences of $p l s, g t f C$, and $g f t D$ in Y24 could improve its virulence and resistance. Gene orf58 encodes a two-component sensor histidine kinase, while gene orf57 encodes a response regulator. Both genes were only found in three S. epidermidis strains (ATCC 12228, PM221 and SEI), depending on the NCBI nucleotide collection $(\mathrm{nr} / \mathrm{nt})$ database. What are the functions of the two component system in S. epidermidis strains needs to be further studied.

\section{AUTHOR CONTRIBUTIONS}

CT performed the experiments, analyzed the experiment data, and wrote the manuscript. ZW performed the experiments. $\mathrm{HX}$ and XZ designed the experiments, analyzed the result, and reviewed the manuscript.

\section{FUNDING}

This work was supported by two grants from the National Natural Science Foundation of China (Grant Nos. 31602023 and 31372282) and the China Thousand Talents Program. This work was also partially supported from a discovery grant by the Natural Sciences and Engineering Research Council of Canada (Fund No. RGPIN-2016-04715).

\section{SUPPLEMENTARY MATERIAL}

The Supplementary Material for this article can be found online at: https://www.frontiersin.org/articles/10.3389/fmicb. 2018.01031/full\#supplementary-material

FIGURE S1 | PCR results confirming the formation of extrachromosomal circular intermediate using different primer sets.

TABLE S1 | Oligonucleotides used in this work.

TABLE S2 | Predicted ORFs in the SCC elements and ACME of S. epidermidis Y24.

TABLE S3 | Defensive systems and origin of the strains.

Staphylococcus aureus from outpatients in Northern Japan: increasing tendency of ST5/ST764 MRSA-IIa with arginine catabolic mobile element. Microb. Drug Resist. 23, 616-625. doi: 10.1089/mdr.2016. 0176

Aziz, R. K., Bartels, D., Best, A. A., DeJongh, M., Disz, T., Edwards, R. A., et al. (2008). The RAST Server: rapid annotations using subsystems technology. BMC Genomics 9:75. doi: 10.1186/1471-2164-9-75

Bartels, M. D., Hansen, L. H., Boye, K., Sorensen, S. J., and Westh, H. (2011). An unexpected location of the arginine catabolic mobile element (ACME) in 
a USA300-related MRSA strain. PLoS One 6:e16193. doi: 10.1371/journal.pone. 0016193

Bleiziffer, I., Eikmeier, J., Pohlentz, G., McAulay, K., Xia, G., Hussain, M., et al. (2017). The plasmin-sensitive protein pls in methicillin-resistant Staphylococcus aureus (MRSA) is a glycoprotein. PLoS Pathog. 13:e1006110. doi: 10.1371/ journal.ppat.1006110

Brody, T., Yavatkar, A. S., Lin, Y., Ross, J., Kuzin, A., Kundu, M., et al. (2008). Horizontal gene transfers link a human MRSA pathogen to contagious bovine mastitis bacteria. PLoS One 3:e3074. doi: 10.1371/journal.pone.000 3074

Clinical Laboratory Standards Institute [CLSI] (2015). Performance Standards for Antimicrobial Disk, and Dilution Susceptibility Tests for Bacteria Isolated from Animals; 3rd Informational Supplement. Wayne, PA: CLSI.

Darling, A. E., Mau, B., and Perna, N. T. (2010). progressiveMauve: multiple genome alignment with gene gain, loss and rearrangement. PLoS One 5:e11147. doi: 10.1371 /journal.pone.0011147

Diep, B. A., Gill, S. R., Chang, R. F., Phan, T. H., Chen, J. H., Davidson, M. G., et al. (2006). Complete genome sequence of USA300, an epidemic clone of community-acquired meticillin-resistant Staphylococcus aureus. Lancet 367, 731-739. doi: 10.1016/S0140-6736(06)68231-7

Diep, B. A., Stone, G. G., Basuino, L., Graber, C. J., Miller, A., des Etages, S. A., et al. (2008). The arginine catabolic mobile element and staphylococcal chromosomal cassette mec linkage: convergence of virulence and resistance in the USA300 clone of methicillin-resistant Staphylococcus aureus. J. Infect. Dis. 197, 1523-1530. doi: 10.1086/587907

Espedido, B. A., Steen, J. A., Barbagiannakos, T., Mercer, J., Paterson, D. L., Grimmond, S. M., et al. (2012). Carriage of an ACME II variant may have contributed to methicillin-resistant Staphylococcus aureus sequence type 239like strain replacement in Liverpool Hospital, Sydney, Australia. Antimicrob. Agents Chemother. 56, 3380-3383. doi: 10.1128/AAC.00013-12

Glaser, P., Martins-Simoes, P., Villain, A., Barbier, M., Tristan, A., Bouchier, C., et al. (2016). Demography and intercontinental spread of the USA300 community-acquired methicillin-resistant Staphylococcus aureus lineage. MBio 7, e02183-15. doi: 10.1128/mBio.02183-15

Hon, P. Y., Chan, K. S., Holden, M. T., Harris, S. R., Tan, T. Y., Zu, Y. B., et al. (2013). Arginine catabolic mobile element in methicillin-resistant Staphylococcus aureus (MRSA) clonal group ST239-MRSA-III isolates in Singapore: implications for PCR-based screening tests. Antimicrob. Agents Chemother. 57, 1563-1564. doi: 10.1128/AAC.02518-12

Hsu, L. Y., Harris, S. R., Chlebowicz, M. A., Lindsay, J. A., Koh, T. H., Krishnan, P., et al. (2015). Evolutionary dynamics of methicillin-resistant Staphylococcus aureus within a healthcare system. Genome Biol. 16:81. doi: 10.1186/s13059015-0643-z

International Working Group on the Classification of Staphylococcal Cassette Chromosome Elements (2009). Classification of staphylococcal cassette chromosome mec (SCCmec): guidelines for reporting novel SCCmec elements. Antimicrob. Agents Chemother. 53, 4961-4967. doi: 10.1128/AAC. 00579-09

Ito, T., Katayama, Y., and Hiramatsu, K. (1999). Cloning and nucleotide sequence determination of the entire mec DNA of pre-methicillin-resistant Staphylococcus aureus N315. Antimicrob. Agents Chemother. 43, 1449-1458.

Josefsson, E., Juuti, K., Bokarewa, M., and Kuusela, P. (2005). The surface protein Pls of methicillin-resistant Staphylococcus aureus is a virulence factor in septic arthritis. Infect. Immun. 73, 2812-2817. doi: 10.1128/IAI.73.5.2812-2817.2005

Jung, J., Song, E. H., Park, S. Y., Lee, S. R., Park, S. J., Sung, H., et al. (2016). Emergence of panton-valentine leucocidin-positive ST8-methicillin-resistant Staphylococcus aureus (USA300 clone) in Korea causing healthcare-associated and hospital-acquired bacteraemia. Eur. J. Clin. Microbiol. Infect. Dis. 35, 1323-1329. doi: 10.1007/s10096-016-2668-y

Li, R., Zhu, H., Ruan, J., Qian, W., Fang, X., Shi, Z., et al. (2010). De novo assembly of human genomes with massively parallel short read sequencing. Genome Res. 20, 265-272. doi: 10.1101/gr.097261.109

Liu, P., Xue, H., Wu, Z., Ma, J., and Zhao, X. (2016). Effect of bla regulators on the susceptible phenotype and phenotypic conversion for oxacillin-susceptible mecA-positive staphylococcal isolates. J. Antimicrob. Chemother. 71, 21052112. doi: 10.1093/jac/dkw123

McManus, B. A., Coleman, D. C., Deasy, E. C., Brennan, G. I., O’ Connell, B., Monecke, S., et al. (2015). Comparative genotypes, staphylococcal cassette chromosome mec (SCCmec) genes and antimicrobial resistance amongst Staphylococcus epidermidis and Staphylococcus haemolyticus isolates from infections in humans and companion animals. PLoS One 10:e0138079. doi: 10.1371/journal.pone.0138079

Mukhopadhyay, R., Rosen, B. P., Phung, L. T., and Silver, S. (2002). Microbial arsenic: from geocycles to genes and enzymes. FEMS Microbiol. Rev. 26, 311-325. doi: 10.1111/j.1574-6976.2002.tb00617.x

Onishi, M., Urushibara, N., Kawaguchiya, M., Ghosh, S., Shinagawa, M., Watanabe, N., et al. (2013). Prevalence and genetic diversity of arginine catabolic mobile element (ACME) in clinical isolates of coagulase-negative staphylococci: identification of ACME type I variants in Staphylococcus epidermidis. Infect. Genet. Evol. 20, 381-388. doi: 10.1016/j.meegid.2013. 09.018

Otto, M. (2009). Staphylococcus epidermidis-the 'accidental' pathogen. Nat. Rev. Microbiol. 7, 555-567. doi: 10.1038/nrmicro2182.

Otto, M. (2013). Coagulase-negative staphylococci as reservoirs of genes facilitating MRSA infection: Staphylococcal commensal species such as Staphylococcus epidermidis are being recognized as important sources of genes promoting MRSA colonization and virulence. Bioessays 35, 4-11. doi: 10.1002/bies. 201200112

Rupp, M. E. (2014). Clinical characteristics of infections in humans due to Staphylococcus epidermidis. Methods Mol. Biol. 1106, 1-16. doi: 10.1007/9781-62703-736-5_1

Sabat, A. J., Ilczyszyn, W. M., van Rijen, M., Akkerboom, V., Sinha, B., Kluytmans, J., et al. (2015). Genome-wide analysis reveals two novel mosaic regions containing an ACME with an identical DNA sequence in the MRSA ST398-t011 and MSSA ST8-t008 isolates. J. Antimicrob. Chemother. 70, 1298-1302. doi: 10.1093/jac/dku531

Sabat, A. J., Kock, R., Akkerboom, V., Hendrix, R., Skov, R. L., Becker, K., et al. (2013). Novel organization of the arginine catabolic mobile element and staphylococcal cassette chromosome mec composite island and its horizontal transfer between distinct Staphylococcus aureus genotypes. Antimicrob. Agents Chemother. 57, 5774-5777. doi: 10.1128/AAC.01321-13

Shibuya, Y., Hara, M., Higuchi, W., Takano, T., Iwao, Y., and Yamamoto, T. (2008). Emergence of the community-acquired methicillin-resistant Staphylococcus aureus USA300 clone in Japan. J. Infect. Chemother. 14, 439-441. doi: 10.1007/ s10156-008-0640-1

Sievert, D. M., Ricks, P., Edwards, J. R., Schneider, A., Patel, J., Srinivasan, A., et al. (2013). Antimicrobial-resistant pathogens associated with healthcareassociated infections: summary of data reported to the National Healthcare Safety Network at the Centers for Disease Control and Prevention, 2009-2010. Infect. Control Hosp. Epidemiol. 34, 1-14.

Sullivan, M. J., Petty, N. K., and Beatson, S. A. (2011). Easyfig: a genome comparison visualizer. Bioinformatics 27, 1009-1010. doi: 10.1093/bioinformatics/btr039

Talan, D. A., Krishnadasan, A., Gorwitz, R. J., Fosheim, G. E., Limbago, B., Albrecht, V., et al. (2011). Comparison of Staphylococcus aureus from skin and soft-tissue infections in US emergency department patients, 2004 and 2008. Clin. Infect. Dis. 53, 144-149. doi: 10.1093/cid/cir308

Thurlow, L. R., Joshi, G. S., Clark, J. R., Spontak, J. S., Neely, C. J., Maile, R., et al. (2013). Functional modularity of the arginine catabolic mobile element contributes to the success of USA300 methicillin-resistant Staphylococcus aureus. Cell Host Microbe 13, 100-107. doi: 10.1016/j.chom.2012.11.012

Thurlow, L. R., Joshi, G. S., and Richardson, A. R. (2012). Virulence strategies of the dominant USA300 lineage of community-associated methicillin-resistant Staphylococcus aureus (CA-MRSA). FEMS Immunol. Med. Microbiol. 65, 5-22. doi: 10.1111/j.1574-695X.2012.00937.x

Urushibara, N., Kawaguchiya, M., Onishi, M., Mise, K., Aung, M. S., and Kobayashi, N. (2016). Novel structures and temporal changes of arginine catabolic mobile elements in methicillin-resistant Staphylococcus aureus genotypes ST5-MRSA-II and ST764-MRSA-II in Japan. Antimicrob. Agents Chemother. 60, 3119-3122. doi: 10.1128/AAC.02356-15

Wu, Z., Li, F., Liu, D., Xue, H., and Zhao, X. (2015). Novel type XII staphylococcal cassette chromosome mec harboring a new cassette chromosome recombinase, CcrC2. Antimicrob. Agents Chemother. 59, 7597-7601. doi: 10.1128/AAC. 01692-15

Xue, H., Wu, Z., Li, L., Li, F., Wang, Y., and Zhao, X. (2015). Coexistence of heavy metal and antibiotic resistance within a novel composite staphylococcal 
cassette chromosome in a Staphylococcus haemolyticus isolate from bovine mastitis milk. Antimicrob. Agents Chemother. 59, 5788-5792. doi: 10.1128/AAC. 04831-14

Xue, H., Wu, Z., Qiao, D., Tong, C., and Zhao, X. (2017). Global acquisition of genetic materials from different bacteria into the staphylococcal cassette chromosome elements of a staphylococcus epidermidis. Int. J. Antimicrob. Agents 50, 581-587. doi: 10.1016/j.ijantimicag.2017.06.015

Zhang, Y. Q., Ren, S. X., Li, H. L., Wang, Y. X., Fu, G., Yang, J., et al. (2003). Genome-based analysis of virulence genes in a non-biofilmforming Staphylococcus epidermidis strain (ATCC 12228). Mol. Microbiol. 49, 1577-1593. doi: 10.1046/j.1365-2958.2003.03671.x
Conflict of Interest Statement: The authors declare that the research was conducted in the absence of any commercial or financial relationships that could be construed as a potential conflict of interest.

Copyright (๑) 2018 Tong, Wu, Zhao and Xue. This is an open-access article distributed under the terms of the Creative Commons Attribution License (CC BY). The use, distribution or reproduction in other forums is permitted, provided the original author(s) and the copyright owner are credited and that the original publication in this journal is cited, in accordance with accepted academic practice. No use, distribution or reproduction is permitted which does not comply with these terms. 